\title{
Multiple Amino Acids Inhibit Postharvest Senescence of Broccoli
}

\author{
Muhammad Sohail, Ron Baden Howe Wills *(D), Michael C. Bowyer and Penta Pristijono (D)
}

check for updates

Citation: Sohail, M.; Wills, R.B.H.; Bowyer, M.C.; Pristijono, P. Multiple Amino Acids Inhibit Postharvest Senescence of Broccoli. Horticulturae 2021, 7, 71. https://doi.org/ 10.3390/horticulturae7040071

Academic Editor: Tianbao Yang and Jorge M. Fonseca

Received: 22 March 2021

Accepted: 2 April 2021

Published: 4 April 2021

Publisher's Note: MDPI stays neutral with regard to jurisdictional claims in published maps and institutional affiliations.

Copyright: (c) 2021 by the authors. Licensee MDPI, Basel, Switzerland. This article is an open access article distributed under the terms and conditions of the Creative Commons Attribution (CC BY) license (https:/ / creativecommons.org/licenses/by/ $4.0 /)$.
School of Environmental and Life Sciences, University of Newcastle, Ourimbah, NSW 2258, Australia; muhammad.sohail@uon.edu.au (M.S.); michael.bowyer@newcastle.edu.au (M.C.B.); penta.pristijono@newcastle.edu.au (P.P.)

* Correspondence: ron.wills@newcastle.edu.au

Abstract: The function of free amino acids in protein synthesis, as a source of energy and unique roles in catabolism have been well studied in plant development but their function in postharvest fruit and vegetables has received little attention. This study evaluated 11 amino acids-arginine, alanine, aspartic acid, glutamic acid, glycine, ornithine, phenylalanine, serine, tyrosine, tryptophan and valine-on the development of senescence of broccoli. Broccoli florets were dipped in $5 \mathrm{mM}$ solution of amino acids, then stored at $10^{\circ} \mathrm{C}$ in air containing $0.1 \mu \mathrm{L} \mathrm{L}^{-1}$ ethylene. Senescence was assessed by green life, ethylene production, respiration rate and ion leakage. Green life was increased by all the amino acids except valine. Similarly, ethylene production and ion leakage were decreased by all the amino acids except valine, while respiration rate was reduced by all amino acids. It is speculated that the early reduction in ethylene production could be the mechanism by which the amino acids delayed senescence. The beneficial effect of naturally occurring amino acids in inhibiting senescence has potential commercial relevance, as the amino acids have Generally Recognised As Safe (GRAS) status which should assist gain regulatory approval, and gain acceptance by consumers wary of synthetic chemicals on foods.

Keywords: amino acids; broccoli; green colour; ethylene; respiration; ion leakage

\section{Introduction}

Plants synthesise the 20 amino acids that comprise the monomeric units of all proteins in plant and animal systems. These amino acids can also be utilized as an energy source. In addition, each amino acid has a unique role in maintaining some aspect(s) of normal metabolism [1]. Postharvest fruit and vegetables need to sustain normal cellular function and integrity to remain in a marketable condition. However, with the lack of energy or metabolic inputs into produce after harvest, it would seem likely that during storage and handling some amino acids will decrease to levels where they are not able to sustain normal metabolic activity, which should lead to enhanced senescence.

Over the last decade, a range of studies has been conducted on the potential use of some amino acids to control postharvest losses of fresh fruit and vegetables. Most reports have been on the effects of arginine and cysteine. Studies on intact produce have shown that general senescence was inhibited by arginine applied to button mushroom [2], green asparagus [3], strawberry [4] and tomato [5], while cysteine inhibited senescence of litchi [6], longan [7], pak choy, parsley and peppermint leaves [8]. Chilling injury symptoms were suppressed by arginine applied to pomegranate [9], tomato [10], and by cysteine on plum [11]. Studies on enzymic browning of fresh cut produce have reported that arginine inhibited browning of apple and lettuce [12] while cysteine reduced browning of lettuce [13], potato [14], pear [15], banana, mushroom and apple [16]. Of the other amino acids, phenylalanine was found to inhibit rotting of mango, avocado, citrus and strawberry [17] while glutamic acid inhbited rotting of pear [18], tomato [19], and methionine inhibited senescence of litchi [20]. 
Only two comparative studies of amino acids have been sourced. Ali et al. [21] examined five amino acids, valine, glycine, cysteine, methionine and phenylalanine, for the inhibition of browning in cut potatoes. They found effects varied between amino acids and concentration but comparison at a dip concentration of $10 \mathrm{mM}$ showed inhibition by valine and methionine $>$ cysteine $>$ glycine and phenylalanine, with the latter two amino acids only showing a small inhibition of browning. Sohail et al. [22] evaluated three amino acids, arginine, cysteine and methionine for the inhibition of senescence of broccoli. They found senescence, as measured by loss of green colour, ethylene production and respiration, was equally inhibited by the three amino acids.

The present paper extends the Sohail et al. [22] study on broccoli senescence to evaluate an additional ten amino acids, alanine, aspartic acid, glutamic acid, glycine, ornithine, phenylalanine, serine, tryptophan, tyrosine and valine. To allow comparison with the Sohail et al. [22] study, arginine was included as a benchmark of effectiveness and their most effective dip concentration of $5 \mathrm{mM}$ was utilised. The primary measure of senescence was loss of green colour that was assessed as green life. Ethylene production, respiration rate and ion leakage were also included as indicators of senescence.

\section{Materials and Methods}

\subsection{Broccoli Treatment}

Freshly harvested broccoli heads (Brassica oleracea var. italica) were collected from a produce outlet near the University of Newcastle on the Central Coast, NSW, Australia and transported to the laboratory within one hour. Broccoli heads without any physical defects were cut into uniform florets that were randomly distributed into all treatments in an experiment. Each treatment unit consisted of 10 florets with a total weight of about $150 \mathrm{~g}$. The florets in a unit were dipped for five minutes in a $5 \mathrm{mM}$ solution of the L-isomer of arginine, alanine, aspartic acid, glutamic acid, glycine, ornithine, phenylalanine, serine, tyrosine, tryptophan or valine (Sigma Aldrich, Castle Hill, Australia) containing a wetting agent (Tween 20) at $0.5 \mathrm{~g} \mathrm{~L}^{-1}$. In an experiment, each treatment was applied to three replicate units and each experiment was conducted on three batches of produce obtained at monthly intervals.

After allowing excess water to drain from florets, the treated units were air dried using a pedestal fan for three hours at $20^{\circ} \mathrm{C}$ then placed into separate $0.8 \mathrm{~L}$ plastic containers that were fitted with inlet and outlet ports in the lid. The containers were stored at $10^{\circ} \mathrm{C}$ in an air stream containing $0.1 \mu \mathrm{L} \mathrm{L}^{-1}$ ethylene to simulate a commercial environment likely to be found in commercial storage and transport [23]. Polyethylene tubes (5 $\mathrm{mm}$ i.d.) were connected to the inlet port through which humidified air containing $0.1 \mu \mathrm{L} \mathrm{L}^{-1}$ ethylene was passed into the containers at $90 \mathrm{~mL} \mathrm{~min}^{-1}$. The concentration of ethylene was obtained by mixing ethylene from a cylinder $\left(1000 \mu \mathrm{L} \mathrm{L}^{-1}\right)$ with compressed air.

\subsection{Postharvest Quality Assessment}

\subsubsection{Green Life}

The green colour of each floret in a treatment unit was visually assessed daily by a single observer using a scoring scale from 1 to 5 , where: 1 = full green colour, $2=20 \%$ loss of green colour, $3=40 \%$ loss of green colour, $4=60 \%$ loss of green colour, $5=>70 \%$ loss of green colour as described by Al Ubeed et al. [24]. The loss of green colour as assessed by the visual scoring scale was shown by Al Ubeed et al. [24] to be significantly correlated with the measured loss of chlorophyll. In order to obtain an unbiased assessment of green colour, each treatment unit was pre-coded by an independent person and decoded after all units had been scored for colour. At each assessment, the mean colour score for all florets in a unit was calculated. The time for all florets in a treatment unit to reach a mean score of 3.0 was considered as the green life for that unit. 


\subsubsection{Ethylene Production and Respiration Rate}

Endogenous ethylene production and respiration rate (as evolved carbon dioxide) of the treated broccoli were determined during storage by gas chromatography (Nexis GC-2030 Shimadzu, Kyoto, Japan). The system was designed for simultaneous detection of ethylene and carbon dioxide fitted with a flame ionization detector (FID) and thermal conductivity detector (TCD), respectively. Temperature of the FID was $275^{\circ} \mathrm{C}$ and for TCD was $230^{\circ} \mathrm{C}$. The column temperature was set at $210^{\circ} \mathrm{C}$. At each analysis time, each container of broccoli was sealed, and a gas sample $(1 \mathrm{~mL})$ withdrawn from the internal atmosphere in a syringe was analysed. After three hours, another gas sample was withdrawn and analysed. The difference between the two levels of gas was used to calculate ethylene production as $\mathrm{ng} \mathrm{kg}{ }^{-1} \mathrm{~s}^{-1}$ and respiration rate as $\mu \mathrm{g} \mathrm{kg}{ }^{-1} \mathrm{~s}^{-1} \mathrm{CO}_{2}$.

\subsubsection{Ion Leakage}

Ion leakage was determined using a method described by Al Ubeed et al. [24]. Briefly, two disks ( $10 \mathrm{~mm}$ diam $\times 6 \mathrm{~mm}$ deep) were collected using a cork borer from the head tissue of all broccoli florets in a unit. The disks were immediately immersed in deionised water in a glass beaker for two hours at $20^{\circ} \mathrm{C}$. Conductivity of the solution was then measured using a conductivity meter (Model 4071, Jenway, Staffordshire, UK). The solution was then boiled for $15 \mathrm{~min}$ and allowed to cool at $20^{\circ} \mathrm{C}$. The conductivity was re-measured. Ion leakage was calculated as the difference of the initial to final value of the conductivity expressed as a percentage of the initial value.

\subsection{Statistical Analysis}

The data was statistically analysed by 2-way analysis of variance (ANOVA) using Statistical Analysis System-version 9.4 (SAS Institute, Cary, NC, USA). Where there was a significant difference between treatments, the Least Significant Difference (LSD) at $p=0.05$ was calculated and applied to determine the treatments that were significantly different.

\section{Results}

The initial experiment was conducted primarily to confirm the effect of arginine on broccoli harvested in a new season $(2020 / 21)$ but also examined the effect of glycine and phenylalanine. Figure 1 shows that the rate of ethylene production was significantly lower than the water control florets at the initial analysis after $0.6 \mathrm{~d}(15 \mathrm{~h})$ after dipping and remained so at all subsequent storage times $(p<0.001)$.
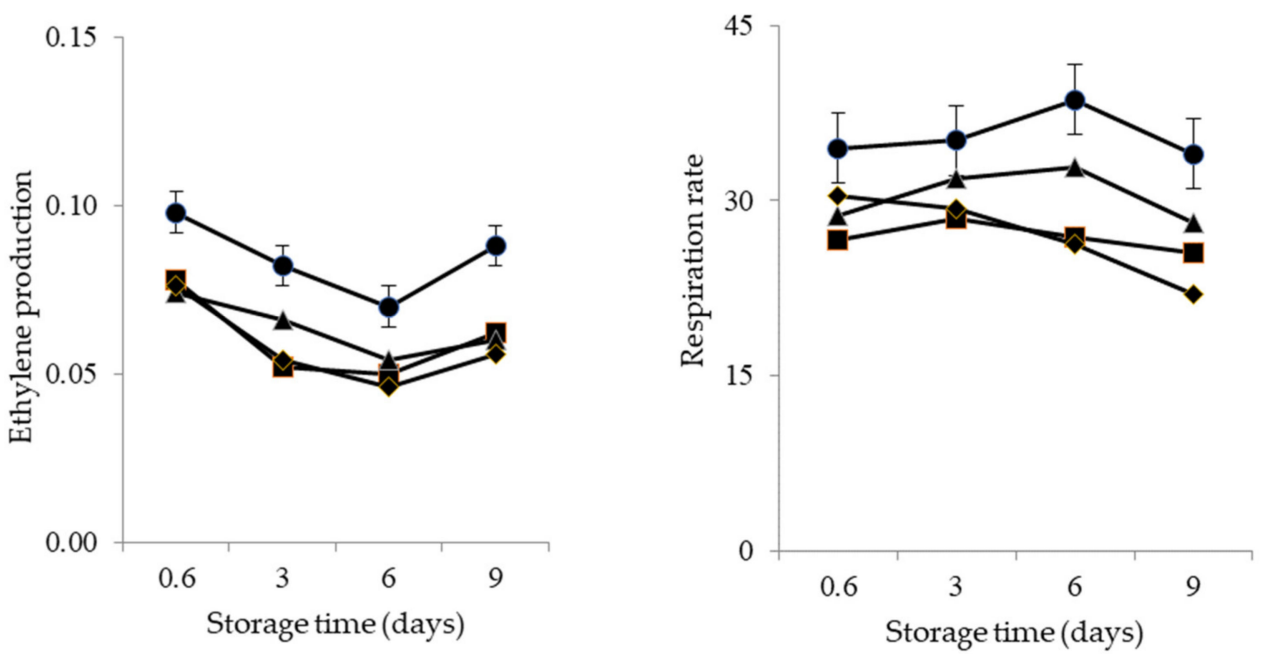

Figure 1. Changes in ethylene production $\left(\mathrm{ng} \mathrm{kg}^{-1} \mathrm{~s}^{-1}\right)$ and respiration rate $\left(\mu \mathrm{g} \mathrm{kg}^{-1} \mathrm{~s}^{-1}\right)$ of broccoli dipped in a $5 \mathrm{mM}$ solution of arginine $(\boldsymbol{\square})$, glycine $(\boldsymbol{\Lambda})$ or phenylalanine $(\boldsymbol{\nabla})$ during subsequent storage at $10^{\circ} \mathrm{C}$. Each ethylene production and respiration rate value is the mean of 9 analyses ( 3 batches $\times 3$ replicates). Control broccoli are denoted by $\bullet$. Error bars are the LSD at $p=0.05$. 
Figure 1 also shows that respiration showed a similar significant trend $(p<0.001)$ with the three amino acids having a lower rate than control florets after $0.6 \mathrm{~d}$ and remaining lower at all subsequent storage times. The mean values for ethylene production and respiration over the storage period are given in Table 1 as there was no significant interaction between treatment and storage time. The data show that the three amino acids were not significantly different in inhibition of ethylene production, but the respiration rate was more strongly inhibited by arginine and phenylalanine than glycine; however, the glycine respiration rate was still lower than the control. Table 1 also shows the loss of green colour (expressed as green life) of broccoli was significantly extended by the three amino acids with phenylalanine significantly more effective than arginine and glycine.

Table 1. Green life and mean ethylene production and respiration rate of broccoli dipped in a $5 \mathrm{mM}$ solution of arginine, glycine or phenylalanine during storage at $10{ }^{\circ} \mathrm{C}$.

\begin{tabular}{|c|c|c|c|}
\hline Treatment & Green Life (Days) & $\begin{array}{l}\text { Ethylene Production } \\
\quad\left(\mathrm{ng} \mathrm{kg}^{-1} \mathrm{~s}^{-1}\right)\end{array}$ & $\begin{array}{l}\text { Respiration Rate } \\
\left(\mu \mathrm{g} \mathrm{kg} \mathrm{kg}^{-1} \mathrm{~s}^{-1}\right)\end{array}$ \\
\hline Control & $9.2^{a}$ & $0.082^{a}$ & $35.3^{a}$ \\
\hline Arginine & $11.1^{\mathrm{b}}$ & $0.060^{b}$ & $26.8^{c}$ \\
\hline Glycine & $11.0^{\mathrm{b}}$ & $0.064^{b}$ & $30.4^{b}$ \\
\hline Phenylalanine & $12.1^{\mathrm{c}}$ & $0.058^{b}$ & $27.0^{c}$ \\
\hline$L S D(p=0.05)$ & 0.5 & 0.015 & 3.0 \\
\hline
\end{tabular}

Green life values are the mean of 9 assessments ( 3 batches $\times 3$ replicates) and ethylene production and respiration rate values are the mean of 36 analyses ( 3 batches $\times 3$ replicates $\times 4$ storage times). Values within each column not sharing the same superscript are significantly different at $p=0.05$.

The effects of $5 \mathrm{mM}$ dips of eight other amino acids, serine, ornithine, tyrosine, valine, aspartic acid, tryptophan, glutamic acid and alanine were then evaluated with arginine and water as benchmark and control treatments, respectively. Floret green colour was assessed daily to determine green life while ethylene production, respiration rate and ion leakage were analysed after six and nine days storage. The results are presented in Figure 2. The green life of broccoli was significantly higher than control for all the amino acids except for valine, which was not significantly different to control florets. Maximum green life of 11-12 days was achieved with alanine, arginine and ornithine which was about a $45 \%$ increase in green life over control florets and were significantly greater than that of the other amino acids at about 10 days which was about a $25 \%$ increase over control florets. Data for ion leakage, ethylene production and respiration rate showed a significant effect of treatment and time but no significant interaction between treatment and time, hence the mean values for analyses conducted at six and nine days is presented. Ion leakage and ethylene production showed all amino acids except valine were significantly lower than control broccoli with no significant difference between the seven amino acids-the reduction relative to control florets averaged about $30 \%$ for both factors. The effect on respiration rate was slightly different in that all eight amino acids, including valine, showed a significant decrease over control florets with arginine and alanine being significantly lower than the other amino acids-the reduction due to arginine and alanine was about $30 \%$ and about $20 \%$ for the other amino acids.

The amount of amino acid added to florets was determined by weighing a unit then dipping florets in water and a $5 \mathrm{mM}$ solution of arginine, alanine, aspartic acid, ornithine, phenylalanine, serine or valine for $5 \mathrm{~min}$. as in the previous experiments. After allowing excess water to drain, each unit was re-weighed. The solution uptake by florets was similar in all treatments with the mean uptake being $234 \mathrm{~mL} \mathrm{~kg}^{-1}$ of broccoli. The uptake of amino acid from the $5 \mathrm{mM}$ solution was thus $1.2 \mathrm{mmol} \mathrm{kg}^{-1}$ broccoli. 

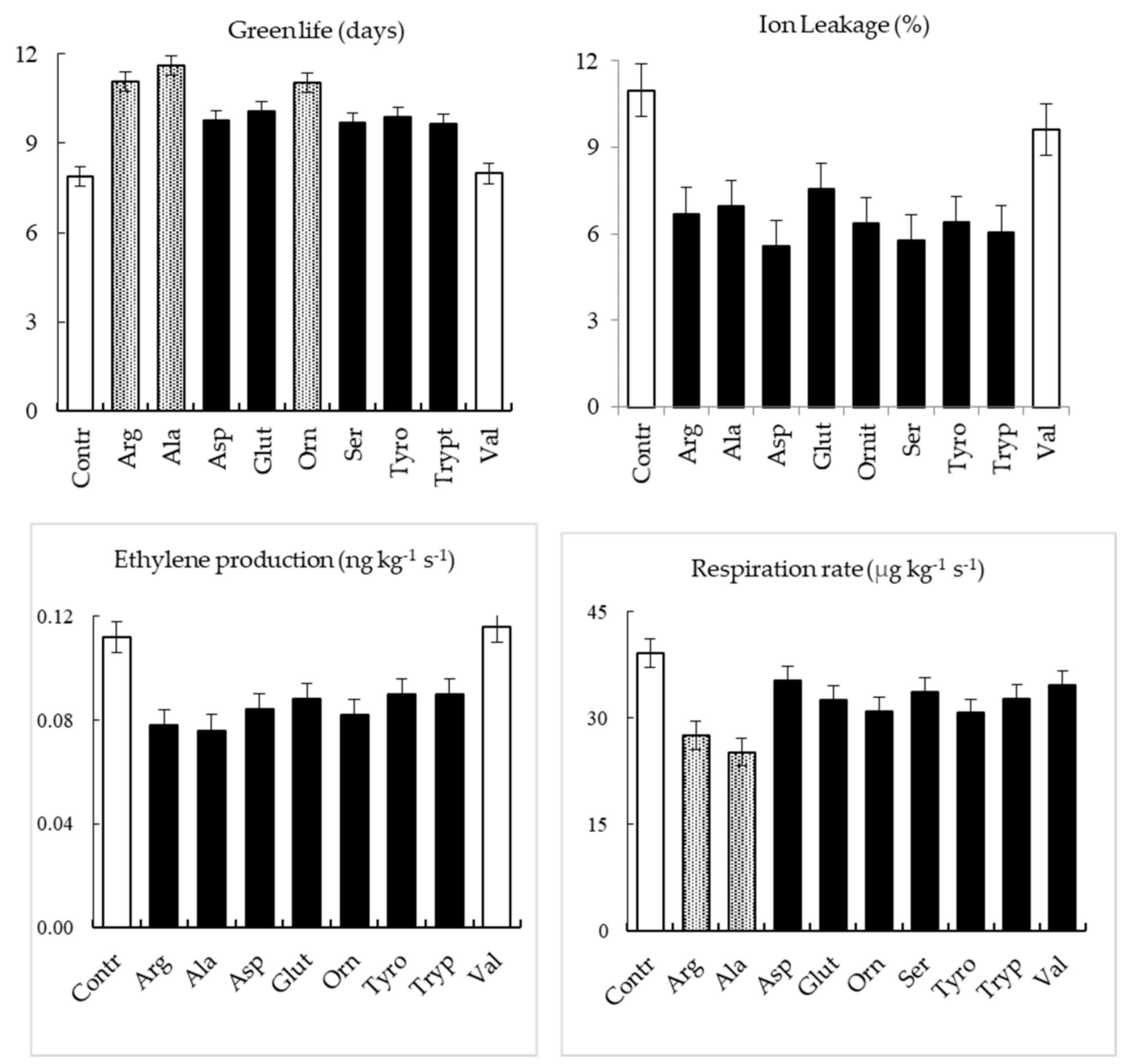

Figure 2. Green life, ion leakage, ethylene production and respiration rate of broccoli dipped in a $5 \mathrm{mM}$ solution of arginine, serine, ornithine, tyrosine, valine, aspartic acid, tryptophan, glutamic acid or alanine during storage at $10{ }^{\circ} \mathrm{C}$. Each green life value is the mean of 9 assessments ( 3 batches $\times 3$ replicates), ion leakage, ethylene and respiration values are the mean of 18 analyses ( 3 batches $\times 3$ replicates $\times 2$ storage times of 6 and 9 days). Amino acid bars with no fill are not significantly different to control, solid bars are significantly different to control, and hatched bars are significantly different to other amino acids, all at $p<0.05$. Error bars are the LSD at $p=0.05$.

\section{Discussion}

Inhibition of the loss of green colour, as measured by the extension in green life, of broccoli florets was achieved by all amino acid solutions except valine. When these findings are coupled with those reported for cysteine and methionine on broccoli [22], 12 of the 13 amino acids included in these studies extended green life. While there were some statistically significant differences between amino acids in the magnitude of green life extension in a particular experiment, it could be considered that the 12 amino acids are similarly effective and achieved an average 33\% increase in green life. The findings of almost universal inhibition of senescence by the amino acids evaluated, was somewhat unexpected due to the differing catabolic pathways of each amino acid. In order to find the most effective amino acid, or even combination of amino acids, it is considered that all the natural amino acids should be evaluated and on a wide range of produce. The potential benefit of amino acids on other produce was demonstrated by Sohail et al. [25] who found that arginine, cysteine and methionine inhibited senescence of six other leafy green vegetables - pak choy, spinach, choy sum, coriander, parsley and rocket. A commercial advantage of using amino acids to inhibit senescence is that they have Generally Recognised As Safe (GRAS) status which should assist in gaining regulatory approval for use on foods, and being naturally occurring substrates should be acceptable for use on organic produce. 
Their natural status should also support acceptance by consumers who are becoming increasingly wary of the addition of synthetic chemicals to foods.

It is noted that the amount of amino acid added to florets at $1.2 \mathrm{mmol} \mathrm{kg}^{-1}$ is quite low compared to the level of free amino acids that Gomes and Rosa [26] found to be present at harvest in 11 broccoli cultivars grown in Portugal of $22 \mathrm{mmol} \mathrm{kg}^{-1}$ (range, $18-32 \mathrm{mmol} \mathrm{kg}^{-1}$ ). Acknowledging that different cultivars are grown in Australia and that Gomes and Rosa [26] found free amino acid levels differed between growing seasons, it would seem that the addition of $1.2 \mathrm{mmol} \mathrm{kg}^{-1}$ represents about $5 \%$ of the possible free amino acid pool within broccoli tissues. It is expected that not all the added amino acid would be incorporated into cell tissues with an unknown proportion remaining on the external surfaces of florets. Hence, it would seem that the beneficial effect of the amino acids was achieved with only a relatively small addition to the free amino acid pool within broccoli.

From a metabolic perspective, it can only be speculated as to the mode of action of the effective amino acids. One possibility is that all amino acids can be used as an energy source by broccoli as Hildebrandt et al. [1] noted that senescing plant tissues degrade proteins to release free amino acids for energy production. However, it is difficult to foresee that all the amino acids would be utilised for energy production to the same extent. In addition, the omission of an effect from valine would tend to negate such a hypothesis as valine metabolism is linked to the TCA respiratory cycle through its conversion to acetyl-CoA [1].

All the amino acids, except valine, were also found to decrease in the rate of ethylene production and the extent of ion leakage with no significant difference between the effective amino acids. Ethylene is well known as a promotor of general senescence [27]. The decrease in ethylene production was observed within the first day after dipping in amino acid solution and could be a primary metabolic action that leads to inhibition of senescence in general, which includes chlorophyll loss. Inhibition of ion leakage, along with inhibition of PAL activity and retention of antioxidant activity was found by Sohail et al. [22] to occur subsequently to reduction in ethylene production. While a range of senescence-related factors have been measured in the various published studies with individual amino acids, only Al Ubeed et al. [8] and Kumar et al. [28] examined the effect on ethylene production. Similar to this study, Al Ubeed et al. [8] found a cysteine dip reduced ethylene production of pak choy, parsley and peppermint leaves within the first day after dipping, while Kumar et al. [28] found reduced ethylene production and senescence of chrysanthemum flower after dipping in phenylalanine solution. Their findings thus reinforce the view that reduced ethylene production could be a key metabolic factor of the amino acids that leads to an extended postharvest life. The current study also found a decrease in the respiration rate was affected by all the amino acids. Respiration is an indicator of overall metabolism and its reduction could lead to a reduced rate of loss of green colour and ion leakage. However, it would seem not to be the primary driver of reduced senescence as valine was also effective in decreasing respiration, and arginine, alanine and phenylalanine had significantly lower respiration than the other amino acids. No explanation can be offered as to why valine had no effect on broccoli senescence, nor how all the other amino acids could similarly inhibit ethylene production given their diverse metabolic function in plants.

\section{Conclusions}

Given their diversity of metabolic paths in plants, it was somewhat surprising that 10 amino acids were similarly beneficial in inhibiting the four aspects of senescence included in the study. While it is not possible to be definitive about their modes of action, regardless of whether a single or multiple modes of actions are responsible for their effectiveness in inhibiting senescence of broccoli, it highlights that further studies should be conducted on all amino acids and on a wide range of produce. This is due to amino acids being attractive as an acceptable commercial treatment from a consumer and regulatory perspective and for use on organic produce. It is also possible that further studies may find 
specific amino acids are more effective on specific produce and efficiency may be improved with other modes of application other than as an aqueous dip.

Author Contributions: Conceptualization, R.B.H.W. and M.C.B.; methodology, M.C.B. and P.P.; validation, R.B.H.W.; formal analysis, M.S. and P.P.; investigation, M.S.; resources, P.P.; data curation, M.S.; writing—original draft preparation, M.S.; writing-review and editing, R.B.H.W.; visualization, M.S.; supervision, M.C.B. and P.P. All authors have read and agreed to the published version of the manuscript.

Funding: This research received no external funding.

Institutional Review Board Statement: Not applicable.

Informed Consent Statement: Not applicable.

Acknowledgments: M.S. acknowledges the financial support of the University of Newcastle Australia in the form of UNIPRS and UNRSC scholarship for carrying out this research as a part of his PhD study.

Conflicts of Interest: The authors declare no conflict of interest.

\section{References}

1. Hildebrandt, T.M.; Nunes Nesi, A.; Araujo, W.L.; Braun, H.P. Amino acid catabolism in plants. Mol. Plant 2015, 8, 1563-1579. [CrossRef] [PubMed]

2. Li, B.; Ding, Y.; Tang, X.; Wang, G.; Wu, S.; Li, X.; Huang, X.; Qu, T.; Chen, J.; Tang, X. Effect of L-arginine on maintaining storage quality of the white button mushroom (Agaricus bisporus). Food Bioprocess. Technol. 2019, 12, 563-574. [CrossRef]

3. Wang, X.; Gu, S.; Chen, B.; Huang, J.; Xing, J. Effect of postharvest L-arginine or cholesterol treatment on the quality of green asparagus (Asparagus officinalis L.) spears during low temperature storage. Sci. Hortic. 2017, 225, 788-794. [CrossRef]

4. Shu, P.; Min, D.; Ai, W.; Li, J.; Zhou, J.; Li, Z.; Zhang, X.; Shi, Z.; Sun, Y.; Jiang, Y.; et al. L-arginine treatment attenuates postharvest decay and maintains quality of strawberry fruit by promoting nitric oxide synthase pathway. Postharvest. Biol. Technol. 2020, 168, 111253. [CrossRef]

5. Zheng, Y.; Sheng, J.; Zhao, R.; Zhang, J.; Lv, S.; Liu, L.; Shen, L. Preharvest L-arginine treatment induced postharvest disease resistance to Botrysis cinerea in tomato fruits. J. Agric. Food Chem. 2011, 59, 6543-6549. [CrossRef] [PubMed]

6. Ali, S.; Khan, A.S.; Malik, A.U. Postharvest L-cysteine application delayed pericarp browning, suppressed lipid peroxidation and maintained antioxidative activities of litchi fruit. Postharvest. Biol. Technol. 2016, 121, 135-142. [CrossRef]

7. Li, T.; Wu, Q.; Zhou, Y.; Yun, Z.; Duan, X.; Jiang, Y. L-Cysteine hydrochloride delays senescence of harvested longan fruit in relation to modification of redox status. Postharvest. Biol. Technol. 2018, 143, 35-42. [CrossRef]

8. Al Ubeed, H.M.S.; Wills, R.B.H.; Bowyer, M.C.; Golding, J.B. Inhibition of postharvest senescence of green leafy vegetables by exogenous D-cysteine and L-cysteine as precursors of hydrogen sulphide. J. Hortic. Sci. Biotechnol. 2019, 94, 620-626. [CrossRef]

9. Babalar, M.; Pirzad, F.; Sarcheshmeh, M.A.A.; Talaei, A.; Lessani, H. Arginine treatment attenuates chilling injury of pomegranate fruit during cold storage by enhancing antioxidant system activity. Postharvest. Biol. Technol. 2018, 137, 31-37. [CrossRef]

10. Zhang, X.; Shen, L.; Li, F.; Meng, D.; Sheng, J. Amelioration of chilling stress by arginine in tomato fruit: Changes in endogenous arginine catabolism. Postharvest. Biol. Technol. 2013, 76, 106-111. [CrossRef]

11. Banin Sogvar, O.; Razavi, F.; Rabiei, V.; Gohari, G. Postharvest application of L-cysteine to prevent enzymatic browning of "Stanley" plum fruit during cold storage. J. Food Process. Preserv. 2020, 14788. [CrossRef]

12. Wills, R.B.H.; Li, Y. Use of arginine to inhibit browning on fresh cut apple and lettuce. Postharvest. Biol. Technol. 2016, 113, 66-68. [CrossRef]

13. Pace, B.; Capotorto, I.; Ventura, M.; Cefola, M. Evaluation of L-cysteine as anti-browning agent in fresh-cut lettuce processing. J. Food Proces. Preserv. 2015, 39, 985-993. [CrossRef]

14. Cerit, İ.; Pfaff, A.; Ercal, N.; Demirkol, O. Postharvest application of thiol compounds affects surface browning and antioxidant activity of fresh-cut potatoes. J. Food Biochem. 2020, 44, 13378. [CrossRef]

15. Zhou, X.; Xiao, Y.; Meng, X.; Liu, B. Full inhibition of Whangkeumbae pear polyphenol oxidase enzymatic browning reaction by L-cysteine. Food Chem. 2018, 266, 1-8. [CrossRef]

16. Arpita, S.; Subroto, D.; Pinaki, B.; Bidyut, B. Inhibition of polyphenol oxidase in banana, apple and mushroom by using different antibrowning agents under different conditions. Int. J. Chem. Sci. 2010, 8, S550-S558.

17. Kumar Patel, M.; Maurer, D.; Feygenberg, O.; Ovadia, A.; Elad, Y.; Oren-Shamir, M.; Alkan, N. Phenylalanine: A promising inducer of fruit resistance to postharvest pathogens. Foods 2020, 9, 646. [CrossRef] [PubMed]

18. Jin, L.; Cai, Y.; Sun, C.; Huang, Y.; Yu, T. Exogenous L-glutamate treatment could induce resistance against Penicillium expansum in pear fruit by activating defense-related proteins and amino acids metabolism. Postharvest. Biol. Technol. 2019, 150, 148-157. [CrossRef] 
19. Yang, J.; Sun, C.; Fu, D.; Yu, T. Test for L-glutamate inhibition of growth of Alternaria alternata by inducing resistance in tomato fruit. Food Chem. 2017, 230, 145-153. [CrossRef] [PubMed]

20. Ali, S.; Khan, A.S.; Malik, A.U.; Shaheen, T.; Shahid, M. Pre-storage methionine treatment inhibits postharvest enzymatic browning of cold stored 'Gola' litchi fruit. Postharv. Biol. Technol. 2018, 140, 100-106. [CrossRef]

21. Ali, H.M.; El-Gizawy, A.M.; El-Bassiouny, R.E.I.; Saleh, M.A. The role of various amino acids in enzymatic browning process in potato tubers and identifying the browning products. Food Chem. 2016, 192, 879-885. [CrossRef]

22. Sohail, M.; Wills, R.B.H.; Bowyer, M.C.; Pristijono, P. Beneficial impact of exogenous arginine, cysteine and methionine on postharvest senescence of broccoli. Food Chem. 2021, 338, 128055. [CrossRef] [PubMed]

23. Wills, R.B.H.; Warton, M.A.; Ku, V.V.V. Ethylene levels associated with fruit and vegetables during marketing. Aust. J. Exp. Agric. 2000, 40, 465-470. [CrossRef]

24. Al Ubeed, H.M.S.; Wills, R.B.H.; Bowyer, M.C.; Vuong, Q.V.; Golding, J.B. Interaction of exogenous hydrogen sulphide and ethylene on senescence of green leafy vegetables. Postharvest. Biol. Technol. 2017, 133, 81-87. [CrossRef]

25. Sohail, M.; Wills, R.B.H.; Bowyer, M.C.; Pristijono, P. Impact of exogenous arginine, cysteine and methionine on the postharvest senescence of six green leafy vegetables. J. Hort. Postharvest. Res. 2021, 4, 1-10. [CrossRef]

26. Gomes, M.H.; Rosa, E. Free amino acid composition in primary and secondary inflorescences of 11 broccoli (Brassica oleracea var italica) cultivars and its variation between growing seasons. J. Sci. Food Agric. 2000, 81, 295-299. [CrossRef]

27. Wills, R.B.H. Low ethylene technology in non-optimal storage temperatures. In Advances in Postharvest Fruit and Vegetable Technology; Wills, R.B.H., Golding, J.B., Eds.; CRC Press: Boca Raton, FL, USA, 2015; Chapter 8; pp. 167-190. [CrossRef]

28. Kumar, V.; Hatan, E.; Bar, E.; Davidovich-Rikanati, R.; Doron-Faigenboim, A.; Spitzer-Rimon, B.; Elad, Y.; Alkan, N.; Lewinsohn, E.; Oren-Shamir, M. Phenylalanine increases chrysanthemum flower immunity against Botrytis cinerea attack. Plant J. 2020, 104, 226-240. [CrossRef] [PubMed] 